\title{
Relationship between nondestructive firmness measurements and commercially important ripening fruit stages for peaches, nectarines and plums
}

\author{
Constantino Valero, Carlos H. Crisosto , David Slaughter \\ Departamento de Ingeniería Rural, Universidad Politécnica Madrid, Av. Complutense, Madrid 28040, Spain \\ Department of Plant Sciences, University of California Davis, One Shields Avenue, Davis, CA 95616, USA \\ Department of Biological \& Agriculural Engineering. University of California, Davis, One Shields Avenue, \\ 3042 Bainer Hall, Davis, CA 95616-5294, USA
}

\begin{abstract}
Fruit firmness measurement is a good way to monitor fruit softening and to predict bruising damage during harvest and postharvest handling. Ripening protocols traditionally utilize a destructive penetrometer-type fruit firmness measure to monitor ripening. Until recently, methods of assessing fruit texture properties nondestructively were not commercially available. The nondestructive Sinclair $\mathrm{iQ}^{\mathrm{TM}}$ firmness tester was investigated to monitor ripening and predict bruising susceptibility in stone fruit. This work was carried out on four peach, three plum, and live nectarine cultivars over two seasons. The correlations between destructive and nondestructive firmness measurements were significant $(p$-value $=0.0001)$, although too low for commercial applications as they varied from $r^{2}=0.60-0.71$ according to fruit type. Using a different approach, the relationship between destructive and nondestructive firmness measures was characterized in terms of segregating these fruit according to their stages of ripening. This was done by using discriminant analysis (66-90\% agreement in ripeness stage classification was observed in validation tests). Discriminant analysis consistently segregated nondestructive firmness measured fruit into commercially important classes ("ready to eat", "ready to buy", "mature and immalure"). These represented key ripening stages with different bruising potentials and consumer acceptance. This work points out the importance to relate nondestructive measurements directly to important commercial physiological stages rather than to correlate them with the current standard penetrometer values. Thus, destructive and nondestructive firmness measurements can be directly used to identify the stage of ripeness and potential susceptibility to bruising during postharvest changes. Further work is recommended to evaluate the performance of this nondestructive sensor in segregating fruit according to their stage of ripeness under packinghouse or processing plant conditions.
\end{abstract}

Keywords: Impact firmness sensor; Sinclair $\mathrm{iQ}^{\mathrm{TM}}$ firmness tester; Discriminant analysis; Critical bruising thresholds; "Ready to eat"; "Keady to buy"

\section{Introduction}

Fruit firmness changes have been a reliable way to describe ripening changes and/or predict bruising damage (Kader, 1992; Crisosto et al., 2001; Metheney et al., 2002). The loss of fruit firmness is a physiological process that occurs during fruit maturation/ripening on the tree, during cold storage and retail handling (Delwiche, 1987; Chen, 1996; Abbott, 1999). In most of these previous studies, fruit firmness was measured destruc- tively. When destructive measurements are used, the tendency is to use as few samples as possible which often results in increased lot to lot variability in the parameter measured. Thus, the sample variability became a factor to consider during laboratory studies and/or commercial applications involving destructive firmness measures. Currently, growers, handlers, and produce store managers still rely on traditional destructive penetrometers (Magness and Taylor, 1925) to control their operations. The use of nondestructive firmness measurements, based on elastic tissue properties rather than tissue failure properties, is becoming available for several indusiries (Chen and Tjan, 1998; Abbott, 1999; De Ketelacre et al., 2006). From a commercial point of view, several nondestructive firmness testing systems are being evaluated for packingline and laboratory measurements (Aweta, 2004; 
Greefa, 2004; Sinclair, 2004). Other researchers have been comparing the Sinclair $\mathrm{iQ}^{\mathrm{TM}}$ firmness tester with acoustic methods and other firmness testers on apples, melons, avocados, nectarines and mangos (De Belie et al., 2000; Shmulevich, 2003). The availability of new technology that allows automated nondestructive firmness measurements will allow greater sampling, reducing variability in firmness measurements of bulk lots, and will help to segregate fruit highly susceptible to bruising or fruit with a similar ripening stage from the sample. In addition, the reduction of fruit sample variability commonly associated with destructive measures will improve our research programs.

The relationship between fruit firmness measurements at harvest and postharvest quality, based on fruit susceptibility to mechanical damage during handling and packaging, has been studied in apples (Kunze et al,, 1975) and peaches (Crisosto et al., 2001). The prediction of potential fruit loss due to mechanical damage during harvesting/postharvest handling has been modeled for several commodities (Chen, 1996; Barreiro et al., 1997). For the fresh fruit market, measuring firmness and pulp temperature during postharvest handling (production and retail sites) are key tools for controlling ripening. This provides useful information to manage marketing, storage and shipment decisions for several commodities (Thompson and Crisosto, 2002). The establishment of ripening protocols will allow fruit handlers to meet consumer demands by delivering "ready to eat" fruit at its optimum firmness (Bruhn, 1995).

In addition to comparing nondestructive Sinclair $\mathrm{iQ}^{\mathrm{TM}}$ firmness tester measurements with the standard destructive penetrometer values, this work focused on the direct relationship between nondestructive measurements and relevant fruit texture changes during ripening.

\section{Materials and methods}

\subsection{Fruit material}

Fruit from four peach (Prunus persica (L.) Batsch), five nectarine (P. persica (L.) Batsch), and three plum (Pronis salicina L.) cultivars growing near the University of California, Kearney Agricultural Center (KAC), Parlier, CA were used for this study. All fruit was harvested when commercially mature during the 2002 and 2003 seasons. The peach cultivars tested were the yellow flesh 'Flavorcrest', 'Summer Lady' and 'O'Henry', and white flesh 'Ivory Princess'. The nectarine cultivars were the yellow flesh 'Spring Bright', 'Ruby Diamond', 'Red Diamond' and 'Summer Bright'. The dark and red skinned plum cultivars tested were 'Blackamber', 'Royal Diamond', and 'Rosemary'.

\subsection{Measurements}

Nondestructive fruit impact firmness was determined by using a bench top version of a commercial online impact firmness measurement system (Sinclair $\mathrm{iQ}^{\mathrm{TM}}$ firmness tester, Sinclair Systems International, LLC, Fresno, CA). This device used a pneumatically operated impact head equipped with a piezoelectric sensor. Its output was processed by proprietary software to return a measure of fruit firmness (SFI score) as a number indexed from 0 to 100 with 0 being soft and 100 being firm. (Readers should note that the manufacturer modified the impact firmness index definition by a multiplicative factor of about two between the manufacture of the firmness tester used in this study and subsequent models in order to improve the suitability of the system to a wide range of produce types (Howarth, 2006).) Prior to each use the Sinclair $\mathrm{iQ}^{\mathrm{TM}}$ firmness tester was calibrated using an elastic calibration ball of a known firmness, and the operating pressure and vacuum were adjusted to operate the pneumatic head within $\pm 1.99 \mathrm{kPa}$ of the manufacturer's recommended set points (Howarth, 2002). The impact firmness force was measured at three equatorial positions on each intact fruit.

Peak destructive force measurements using the University of California firmness penetrometer (UCF) were recorded as pounds force (lbf) and converted to Newtons (N). This sensor is equipped with a manual force gauge (Ametek, Hattield, PA), a $7.9 \mathrm{~mm}$ diameter Magness-Taylor probe (Abbott, 1999) and was mounted on the standard University of California style hand-operated press (Western Industrial Supply Co., San Francisco, CA) to minimize loading rate variations associated with the operator. Destructive firmness measurements were taken at three equatorial positions on each fruit, on exactly the same positions as the Sinclair $\mathrm{iQ}^{\mathrm{TM}}$ firmness tester measurements. For the destructive penetrometer measurements, on each labeled position, a piece of skin $\sim 2 \mathrm{~cm}$ in diameter was removed and the penetrometer tip inserted $\sim 5.0 \mathrm{~mm}$ into the flesh.

\subsection{Data analysis}

Linear and nonlinear (polynomial, logarithmic and exponential) regression models between the Sinclair $\mathrm{iQ}^{\mathrm{TM}}$ firmness tester and the UCF flesh firmness values were calculated using regression analysis (STATISTICA for Windows software, StatSoft, Inc., 1995) on a calibration data set using half the samples.

As a second approach to apply this technology to commercial operations, classification of samples into categories was tested. For these analyses, fruit were segregated into two or three classes using previously established firmness criteria, prior to classification analysis. The firmness thresholds defining these classes were chosen based on our previous work that described bruising thresholds and identification of important ripening stages. Plums were segregated into two classes ("ready to eat" and "ready to buy") by using a UCF firmness threshold of $13 \mathrm{~N}$. This threshold was chosen based on our sensory work that demonstrated that plum consumer acceptance increased for fruit with a UCF firmness $\leq 13 \mathrm{~N}$ (Crisosto et al., 2004). Three classes were created by using 13 and $26 \mathrm{~N}$ thresholds. The $26 \mathrm{~N}$ threshold is the minimum firmness that plums can be harvested to avoid bruising during standard postharvest handling (Crisosto et al., 2001). Thus, plums with $\geq 26$ would be considered "mature" or "immature" (called "mature and immature"). Plums between $>13$ and $<26 \mathrm{~N}$ were classified as "ready to buy". For fresh peaches and nectarines, the classification into "ready to eat" and "others" was accomplished by using an $18 \mathrm{~N}$ threshold. A three-group classification was created by using 18 and $35 \mathrm{~N}$ thresholds. Thus, fruit between 18 and $35 \mathrm{~N}$ was considered "ready to buy." The 
fruit above $35 \mathrm{~N}$ was defined as "mature and immature". These firmness thresholds were selected because they indicate critical changes during postharvest ripening and the susceptibility to bruising damage (Crisosto et al., 2001, 2004).

Two classification procedures were applied and compared to evaluate their performance in segregating fruit into these commercially important firmness categories. First, the previously calculated regression models were used to estimate the UCF values based upon the Sinclair $\mathrm{iQ}^{\mathrm{TM}}$ values; then the previously described UCF firmness thresholds were applied to these values and the percentage of correct classifications was calculated. This procedure was applied to both the calibration data set and the validation data set and the classification performance reported separately.

As a second classification procedure, instead of using regression models, discriminant functions were calculated using discriminant analysis (DA) techniques (Valero et al., 2004a,b) with the Sinclair $\mathrm{iQ}^{\mathrm{TM}}$ firmness tester as an independent variable and class membership based upon previously identified UCF thresholds. The classifier was trained using samples from the calibration data set and tested with the fruit from the validation data set. DA provides segregation of each fruit into a category and the percentage of correct classification.

\section{Results and discussion}

The number of fruits measured for each cultivar varied from 41 for 'Ivory Princess' peach to 165 for 'Blackamber' plum covering a wide range of destructive (UCF) and nondestructive Sinclair $\mathrm{iQ}^{\mathrm{TM}}$ firmness tester values (SFI) (Table 1). The sample size tested for most cultivars was $\geq 100$ fruit and was adequate to apply statistical analyses and obtain valid results. Only in the case of 'Ivory Princess' ( $n=41$ ) was the number of samples for an individual cultivar lower than desired. Destructive firmness ranged from 13.3 to $124.5 \mathrm{~N}$ for fresh peaches, $35.6-133.3 \mathrm{~N}$ for nectarines and $4.4-115.6 \mathrm{~N}$ for plums. The nondestructive firmness values ranged from 0 to $18 \mathrm{SFI}$ for peaches, $1-16 \mathrm{SFI}$ for nectarines and $0-13 \mathrm{SFI}$ for plums. These firmness ranges covered low maturity to ripe fruit, including the standard commercial firmness range, which were wide enough to generate regression and/or classification models (Table 1). The precision of the nondestructive and destructive firmness measured was determined by calculating the coefficients of variation (CV) which were very similar at $11 \%$ for the UCF and $15 \%$ for the Sinclair $\mathrm{iQ}^{\mathrm{TM}}$ firmness tester system.

Linear correlation between nondestructive Sinclair $\mathrm{iQ}^{\mathrm{TM}}$ firmness tester values (SFI) and the destructive (UCF) firmness measurements was significant ( $p$-value $\leq 0.005$ ), although the correlations were lower than expected. Coefficients of determination $\left(r^{2}\right)$ calculated for each cultivar were as low as 0.49 and as high as 0.87 . Among these different commercial species, the relationship between these two firmness sensors was fairly high, with $r^{2}=0.69$ attained for peaches, $r^{2}=0.71$ for nectarines and $r^{2}=0.71$ for plums. These $r^{2}$ values indicate that firmness changes detected by one sensor were not perceived in the same way by the other sensor, i.e., $31 \%$ unexplained variability for peaches, $29 \%$ for nectarines and $29 \%$ for plums, which means the relationship between sensors was not directly accounted for by the changes detected by these two sensors. These low correlations between the Sinclair $\mathrm{iQ}^{\mathrm{TM}}$ firmness tester and the UCF confirm that the devices are sensing different fruit tissue physical property changes (elastic versus tissue failure) during ripening. Changes during ripening sensed by the UCF may not be equally detected by the Sinclair $\mathrm{iQ}^{\mathrm{TM}}$ firmness tester. Its signal could be more sensitive to other texture changes related to firmness (Timbers et al., 1965; Fridley et al., 1968). This implies that a direct linear relationship between these two sensors is not the best way to commercially apply the nondestructive Sinclair $\mathrm{iQ}^{\mathrm{TM}}$ firmness tester in the fresh fruit industry.

As the linear correlation between the two sensors was significant but still lower than desired (Table 1), nonlinear regression models (polynomial, exponential, logarithmic, and their combinations) were tested (Table 2). The best-fit nonlinear models between these two sensors were still low $\left(r^{2}=0.55\right)$ for all fruit: $r^{2}=0.72$ for peach and plum, and $r^{2}=0.60$ for nectarine. Thus, the use of these nonlinear models did not improve the

Table 1

The range and linear regression results of penetrometer readings (UCF) and Sinclair $\mathrm{iQ}^{\mathrm{TM}}$ irmness tester values for all cultivars tested

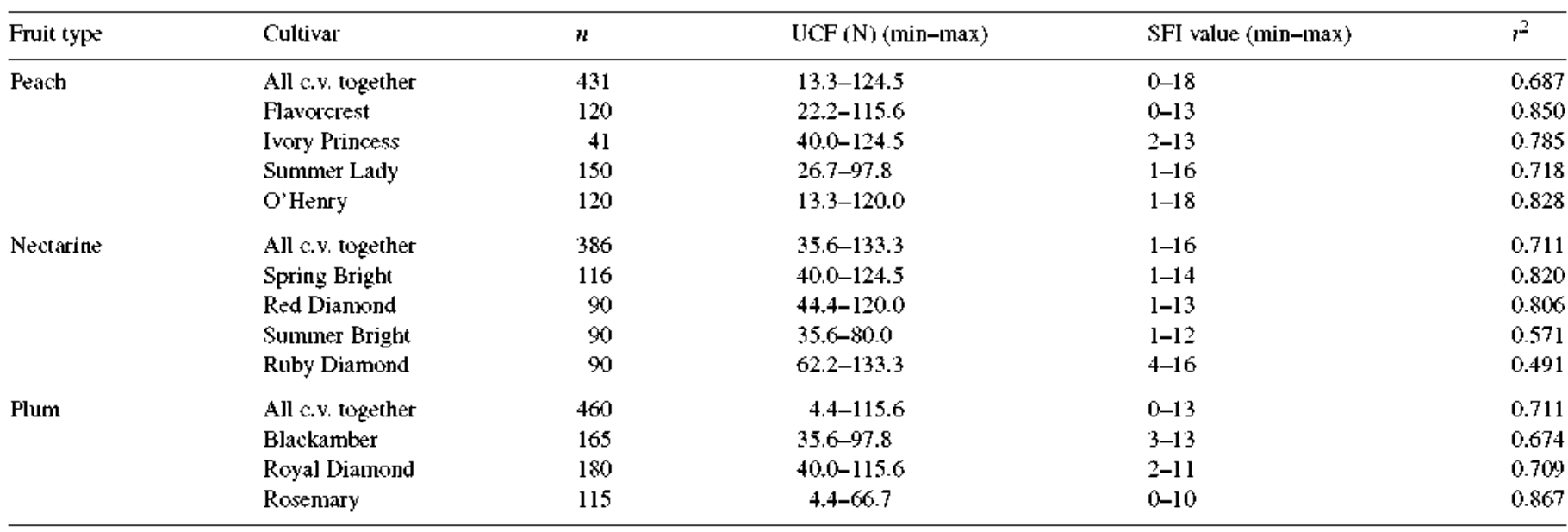

All coefficient of determination values are significant at the $p<0.001$ level. 
Table 2

Summary of nonlinear regression models estimating penetrometer readings (UCF) with Sinclair iQ ${ }^{\mathrm{TM}}$ frmmess values

\begin{tabular}{|c|c|c|c|}
\hline Samples used for calibration & Model estimating penetrometer firmness from impact firmness & $r^{2}$ & Classification tesult (and validation) \\
\hline All fruits $n=3355$ & $\mathrm{UCF}(\mathrm{N})=1.1+0.4 \times \mathrm{iQ}+3.2 \times 10^{-7} \times \mathrm{iQ}{ }^{5}$ & 0.3 & $61 \%(58 \%)$ \\
\hline Nectarine $n=184$ & $\mathrm{UCF}(\mathrm{N})=0.5+7.8 \times 10^{-6} \times \mathrm{iQ}^{4}$ & 0.6 & $88 \%(75 \%)$ \\
\hline Melting peach $t=324$ & $\mathrm{UCF}(\mathrm{N})=5.7+2.9 \times 10^{-3} \times \mathrm{iQ} \mathrm{Q}^{3}-3.2 \times 10^{-18} \times 10^{\mathrm{i} Q}-6.6 \times \log (\mathrm{iQ})$ & 0.7 & $61 \%(54 \%)$ \\
\hline Plum $n=354$ & $\mathrm{UCF}(\mathrm{N})=-62.2+49.1 \times \ln (\mathrm{iQ})+126.6 / \mathrm{iQ}-18.6 \times \mathrm{iQ}^{1 / 2}$ & 0.7 & $98 \%(87 \%)$ \\
\hline
\end{tabular}

Classitication results refer to grouping into three classes, with the thresholds 13 and $26 \mathrm{~N}$ for plums. and 22 and $35 \mathrm{~N}$ for the other fiuits.

relationship between these two sensors for these fruit types. Because correlation levels were not entirely satisfactory, Sinclair $\mathrm{iQ}^{\mathrm{TM}}$ firmness segregation performance was tested, using both the regression models, and discriminant analysis (DA). Results of applying the regression models to estimate $\mathrm{iQ}^{\mathrm{TM}}$ values and then classify samples are shown (Table 2, last column) along with their validations. Sorting of nectarines (calibration set accuracy $=88 \%$, validation set accuracy $=75 \%$ ) and plums (calibration set accuracy $=98 \%$, validation set accuracy $=87 \%$ ) seems to be feasible, while the performance of melting peaches was poorer.

Discriminant analysis segregated fruit consistently into two groups yielding the highest percentages for correctly classifying samples. Plums (calibration set accuracy $=99 \%$, validation set accuracy $=85 \%$ ) and fresh peaches and nectarines (calibration set accuracy $=\sim 92 \%$, validation set accuracy $\sim 82 \%$ ) were well classified between "ready to eat" and other stages such as "ready to buy" and "mature and immature" (Table 3). In addition, DA consistently classified fresh peaches (calibration set accuracy $=84 \%$, validation set accuracy $=70 \%$ ), nectarines (calibration set accuracy $=90 \%$, validation set accuracy $=81 \%$ ), and plums (calibration set accuracy $=82 \%$, validation set accuracy $=74 \%$ ) into three groups (Table 4 ). Considering cultivars independently based upon their calibration classification performance, the highest percentages (calibration set accuracy $>88 \%$ ) of correctly classified samples were obtained for 'Flavorcrest', 'O'Henry', 'Ruby Diamond', 'Royal Diamond' and 'Rosemary' (Table 4).

Looking at the classification performance of each class of the three-class classifier "ready to eat", "ready to buy" and "mature and immature") in more detail we see that the classification performance varied by class, Table 5 . Classification of 431 fresh peaches gave an overall calibration performance of $84 \%$. Out of the 192 "ready to eat" fruit, 186 fruit consistently

Table 3

Discriminant analysis results for classification into two groups ("ready to eat" and "others") using the Sinclair $\mathrm{iQ}^{\mathrm{TM}}$ firmmess tester value (SFI) as predicting variable (calibration set and validation)

\begin{tabular}{llllll}
\hline & \multicolumn{3}{l}{ "Ready to eat" } & & \multicolumn{2}{c}{ "Others" } \\
\cline { 2 - 3 } \cline { 5 - 6 } & $13 \mathrm{~N}^{2}$ & $18 \mathrm{~N}$ & & $26 \mathrm{~N}$ & $35 \mathrm{~N}$ \\
\hline Peaches & - & $92 \%(83 \%)$ & - & $90 \%(86 \%)$ \\
Nectarines & - & $91 \%(80 \%)$ & - & $94 \%(87 \%)$ \\
Plums & $99 \%(85 \%)$ & - & & $82 \%(75 \%)$ & -
\end{tabular}

Percentages correspond to correctly classified samples.

a Pluns were separated into two classes by using a threshold of $13 \mathrm{~N}$. For peaches and nectarines, $18 \mathrm{~N}$ was used as the threshold between the two classes. segregated from the sample $(97 \%)$, as well as 169 "mature and immature" fruit from the 186 mature and immature fruit in the sample (91\%). Fruit at the "ready to buy" stage of ripening, between "ready to eat" and "mature and immature," segregated poorly (13\%) from the 53 fruit samples for this group. In this case, 24 and 22 out of the 53 fruit were classified as "ready to eat" and "mature and immature", respectively. A similar situation occurred for nectarines; classification of 386 nectarines into three groups ("ready to eat", "ready to buy" and "mature and immature") resulted in an overall calibration performance of $90 \%$. Out of the 123 "ready to eat" fruit in the sample, 117 fruit were correctly segregated from this sample $(95 \%)$, as well as 204 "mature and immature" fruit out of the 217 "mature and immature" fruit in the sample (94\%). Fruit at the "ready to buy" stage of ripening, between "ready to eat" and "mature and immature", were not well segregated ( $28 \%$ ) from the 46 fruit samples for this group. In this case, 23 and 10 out of the 46 truit fell as "ready to eat" and "mature and immature", respectively. An $82 \%$ overall plum calibration classification performance was determined. Out of the 57 "ready to eat" fruit in the sample, 54 fruit were correctly segregated from this sample (95\%), as well as 277 "mature and immature" fruit out of the 307 "mature and immature" fruit

Table 4

Results of classification into three groups ("ready to eat", "ready to buy", and "others"), using the Sinclair iQ ${ }^{\mathrm{TM}}$ firmness tester value (SFI), as the predicting variable of tirmness level (UCF)

\begin{tabular}{ll}
\hline Fruit type & $\begin{array}{l}\text { Percentage of well classitied fruits } \\
\text { (and validations) }\end{array}$ \\
\hline Peaches & \\
All c.v. together & $84(70 \%)$ \\
Flavotctest & $93(75 \%)$ \\
Ivory Princess & $85(67 \%)$ \\
Sunner Lady & $80(79 \%)$ \\
O'Henry & $88(68 \%)$ \\
Nectarines & \\
All c.v. together & $90(81 \%)$ \\
Spring Bright & $85(74 \%)$ \\
Red Diamond & $84(66 \%)$ \\
Sunner Bright & $83(80 \%)$ \\
Ruby Dianond & $97(90 \%)$ \\
Plums & \\
All c.v. togethet & $82(74 \%)$ \\
Blackamber & $85(77 \%)$ \\
Royal Diamond & $89(79 \%)$ \\
Rosenary & $95(88 \%)$
\end{tabular}

\footnotetext{
${ }^{3}$ Pluns were separated into three classes by using thresholds of 13 and $26 \mathrm{~N}$. For peaches and nectatines, 18 and $35 \mathrm{~N}$ were used to segregate the fruit into three classes.
} 
Table 5

Classification mattices (calibration set) of each fruit type into three classes

\begin{tabular}{|c|c|c|c|c|c|c|}
\hline \multirow[t]{2}{*}{ Fruit type } & \multirow[t]{2}{*}{ Observed group } & \multirow[t]{2}{*}{ Correctly classified fruits (\%) } & \multicolumn{4}{|c|}{ Ptedicted classifications (SFI) } \\
\hline & & & Ready to eat & Ready to buy & Mature and immature & $n$ \\
\hline \multirow[t]{3}{*}{ Peaches } & $\mathrm{UCF}<18 \mathrm{~N}$ & 97 & 93 & 1 & 2 & 96 \\
\hline & $18<\mathrm{UCF}<35$ & 13 & 12 & 4 & 11 & 27 \\
\hline & $\mathrm{UCF}>35 \mathrm{~N}$ & 91 & 6 & 3 & 85 & 94 \\
\hline Total & & 84 & 111 & 8 & 98 & 217 \\
\hline \multirow[t]{3}{*}{ Nectarines } & $\mathrm{UCF}<18 \mathrm{~N}$ & 95 & 59 & 3 & 0 & 62 \\
\hline & $18<\mathrm{UCF}<35$ & 28 & 12 & 7 & 5 & 24 \\
\hline & $\mathrm{UCF}>35 \mathrm{~N}$ & 94 & 3 & 4 & 102 & 109 \\
\hline Total & & 90 & 74 & 14 & 107 & 195 \\
\hline \multirow[t]{3}{*}{ Plums } & $\mathrm{UCF}<13 \mathrm{~N}$ & 95 & 27 & 1 & 1 & 29 \\
\hline & $13<\mathrm{UCF}<26$ & 48 & 1 & 23 & 25 & 49 \\
\hline & $\mathrm{UCF}>26 \mathrm{~N}$ & 90 & 0 & 15 & 139 & 154 \\
\hline Total & & 82 & 28 & 39 & 165 & 232 \\
\hline
\end{tabular}

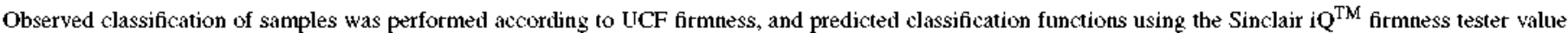
(SFI). Classitication model performance expressed as total percentage of cotrectly classitied fruit. Numbers in bold are cortectly classitied individuals.

in the sample (90\%). Fruit at the "ready to buy" stage of ripening correctly segregated 46 fruit out of $96(48 \%)$. In this case, 1 and 49 out of the 96 fruit classified as "ready to eat" and "mature and immature", respectively. The low ability to identify fruit within the intermediate stage ("ready to buy") in these three fruit types could be explained by the reduced number of samples in this group and/or the difficult definition of this ephemeral stage.

When the performance of the DA classification was studied in detail, it was noticed that groups determined by the UCF firmness thresholds were not so different in terms of SFI values and there was overlapping of SFI values among adjacent firmness groups (borders). Thus, some fruit were incorrectly segregated into two different groups. This overlapping effect was more frequent in the middle group ("ready to buy"), which also was the least populated group. This overlapping was detrimental to the model performance. This also supports the idea that the penetrometer and the Sinclair $\mathrm{iQ}^{\mathrm{TM}}$ firmness tester are not measuring the same texture changes during ripening.

\section{Conclusions}

Linear and nonlinear correlations between destructive (penetrometer) firmness and the nondestructive (Sinclair $\mathrm{iQ}^{\mathrm{TM}}$ firmness tester) measurements were significant, but low. This confirms that the Sinclair $\mathrm{iQ}^{\mathrm{TM}}$ firmness tester sensor is measuring a different physical fruit property (tissue elasticity) during ripening than the UCF (tissue failure); thus, direct comparison of the Sinclair $\mathrm{iQ}^{\mathrm{TM}}$ firmness tester sensor with the UCF penetrometer should be avoided.

Classification methods segregated fruit with an acceptable performance, either using regression functions or discriminant models; both methods produced similar outcomes. Results were more consistent when classifying into different commercially important categories (ripening stages and/or bruising susceptibility) and were more useful than the use of direct correlation between these two sensors. Fruit classifications into groups by nondestructive Sinclair $\mathrm{iQ}^{\mathrm{TM}}$ firmness tester sensors using important ripening stages yielded consistent results for fresh fruit sorted into two or three groups. Thus, classification of plums, nectarines, and peaches into two categories of firmness ("ready to eat" versus "others" or "mature and immature" versus "others") looks like a promising application for the Sinclair $\mathrm{iQ}^{\mathrm{TM}}$ firmness tester $(80-87 \%$ classification accuracy in validation tests). Fruit segregation consistency was reduced to 66-90\% when three categories such as "ready to eat" "ready to buy" and "mature and immature" were used. Therefore, a more detailed study improving the performance of this nondestructive bench model and evaluating this new technology under commercial packinghouse operation conditions should be pursued.

\section{References}

Abbott, J.A., 1999. Quality measurement of fruits and vegetables. Postharv. Biol. Technol. 15, 207-225.

Aweta, 2004. Web page availab]e at http://wwwaweta.n]/ [Accessed 11 January $2004]$.

Barteiro, P., Steinmetz, V., Ruiz-Altisent, M., 1997. Neutal bruise prediction models for fruit handling and machinery evaluation. Comput. Electron. Agric. 18, 91-103.

Butuhn, C.M., 1995. Consumer and retail satisfaction with the quality and size of California peach and nectarines. J. Food Qual. 18, 241-256.

Chen, P., 1996. Quality evaluation technology for agricultural protucts. In: Proceedings of the International Conference on Agricultural Machinery Enginerring. vol. 1, Seoul. Korea. Novenuber 12-15, 1996. pp. 171-204.

Chen, P., Tjan, Y., 1998. A teal-time impact sensing system for online fitmness sensing. In: Proceedings of the Ag. Eng. Conference, Oslo, Paper 98-F-006.

Crisosto. C.H.. Slaughter. D. Garner. D. Boyd. J., 2001. Stone fruit critical bruising thresholds. J. Am. Pomol. Soc. 55, 76-81.

Ctisosto, C.H., Garnet, D., Crisosto, G.M., Bowetman, E., 2004. Increasing 'Blackamber' plum (Pratus salicita Lindell) consumet acceptance. Postharv. Biol. Technol. 34, 237-244.

De Belie. N.. Schotte. S.. Lammeıtyn, J., Nicolai. B.. De Baerdemaeker. J., 2000. Firmness changes of pear fruit before and after harvest with aconstic impulse response technique. J. Agton. Eng. Res. 77, 183-191. 
De Ketelaere, B., Howarth, M.S., Ctezee, L., Lammertyn, J., Viaene, K. . Bulens. I. De Baerdemaeker, J., 2006. Postharvest fitmness changes as measured by acoustic and low-mass impact devices: a comparison of techniques. Postharv. Biol. Technol, 41, 275-284.

Delwiche, M.J., 1987. Theory of fruit firmness sorting by impact forces. Trans. ASAE 30 (4), 1160-1171.

Fridley, R.B. Bradley, R.A.. Rumsey, J.W. Adrian. P.A. 1968. Some aspects of elastic behavior of selected fruits. Trans. ASAE 11 (1), 46-49.

Greefa, 2004. Web page, available at http:/www.greefa.nl [Accessed January 2004].

Howarth. M.S., 2002. Sinclair iQ firmness tester. In: Proceedings of the Ag. Eng. Conference. Budapest. p. 8, Paper 02-IE-006

Howarth, M.S., 2006. The Sinclair iQ firmness tester. Personal Communication. Sinclair Systems International LLC. Ftesno, C.A.

Kader, A.A. (Ed.), 1992. Postharvest Technology of Horticultural Crops, 2nd ed. University of California Division of Agri. and Natural Resources. Publ., p. 3311 .

Kunze, O.R., Aldred, W.H., Reeder, B.D., 1975. Bruising chatacteristics of peaches related to mechanical harvesting. Trans. ASAE 18, 939-945.

Magness, J.R., Taylor, G.F., 1925. An improved type of pressure tester for the determination of fruit maturity. USDA Cir. No. 350.
Metheney, P.D., Ctisosto, C.H., Garnet, D., 2002. Developing canting peach critical bruising thresholds. J. Am. Pomol. Soc. 56 (2), 7578 .

Shmulevich. I., 2003. Nondestiuctive texture assessment of fiujts and vegetables. Acta Hort. 599, 289-296.

Sinclait, 2004. Web pase of the "Sinclait Internal Quality-Firmness Testet". Availab]e at bttp:/wwwsinclair-intl.con [Accessed January 2004].

Thompson. J.F. Crisosto, C., 2002. Handling at destination markets. In: Kader. A.A. (Ed.), Postharvest Technology of Hotticultural Crops, 3td ed. DANR Publication, p. \#3311, Chapter 21.

Timbers. G.E. Staley. L.M. Watson, E.L. 1965. Determining modulus of elasticity in agricultural products by loaded plungers. Agric. Eng. 274275

Valero, C., Ruiz-Altisent, M., Cubeddu, R., Pifferi, A., Taroni, P., Torticelli, A., Valentini, G., Johnson, D.S., Dovet, C.J., 2004a. Detection of internal quality in kiwj with time-domain diffuse reflectance spectroscopy. App. Eng. Agric. $20,223-230$.

Valero, C., Ruiz-Altisent, M., Cubeddu, R., Pifferi, A., Tatoni, P., Torricelli, A., Valentini, G., Johnson, D., Dover, C., 2004b. Selection models for the internal quality of fruit, based on time domain laser reflectance spectroscopy. Biosyst. Eng. 88. 313-323. 